\title{
Neuroleptic-Sensitive Binding Sites in the Nigrostriatal System: Evidence for Differential Distribution of Sigma Sites in the Subtantia Nigra, Pars Compacta of the Cat
}

\author{
Ann M. Graybiel, ${ }^{1}$ Marie-Jo Besson, ${ }^{2}$ and Eckard Weber ${ }^{3}$ \\ Massachusetts Institute of Technology, Department of Brain and Cognitive Sciences, Cambridge, Massachusetts 02139, \\ ¿Laboratoire de Neurochimie-Anatomie, Universite Pierre et Marie Curie, 75005 Paris, France, and ${ }^{3}$ Vollum Institute, \\ Oregon Health Sciences University, Portland, Oregon 97201
}

\begin{abstract}
The sigma site is a recently described binding site to which dextrorotary isomers of certain psychotomimetic benzomorphans bind specifically. Classical and nonclassical neuroleptics also have high affinity for the sigma site, including neuroleptics known to bind to the D2 dopamine receptor. The affinity of some D2-binding neuroleptics for the sigma site has raised the possibility that certain important effects of antipsychotic drugs may relate to the sigma site. Left unresolved has been the question of how these actions could relate to dopaminergic systems. To explore this issue we carried out an autoradiographic binding study of the distribution of the sigma-selective ligand ${ }^{3} \mathrm{H}-\mathrm{DTG}$ in the nigrostriatal system. We report here that haloperidol-displaceable ${ }^{3} \mathrm{H}-\mathrm{DTG}$ binding sites are densely concentrated in an anatomically discrete subdivision of the cat's substantia nigra pars compacta. This zone, identifiable as the striosomeprojecting densocellular zone of the pars compacta, also shows heightened D2-related ligand binding but has reduced D1-related ligand binding relative to other parts of the nigral complex. This evidence suggests that sigma-mediated interactions with dopaminergic systems may occur in the substantia nigra pars compacta and that the functional effects of these interactions may influence the nigrostriatal projection to striosomes differentially.
\end{abstract}

In the original classification of opioid receptors introduced by Martin and his colleagues (Martin et al., 1976; Martin, 1981), sigma receptors were identified as the sites accounting for the "mania" elicited in spinal dogs by $N$-allylnormetazocine (SKF $10,047)$ and related benzomorphans. The psychotomimetic effects of such drugs have since been attributed to nonopioid sites that are not sensitive to naloxone or etorphine (Iwamoto, 1981; Su, 1982; Vaupel, 1983; Tam, 1985). An important differentiation has been made between 2 distinct sites binding SKF 10,047: the phencyclidine (PCP) site, which has a low affinity for the

\footnotetext{
Received Mar. 14, 1988; revised June 2, 1988; accepted June 3, 1988.

We thank Mr. Glenn Holm, Ms. Karen Karuzis, and Ms. Barbara Lee for their help with the autoradiography; and Mr. Henry Hall, who is responsible for the photography. This work was supported by the Seaver Institute, the McKnight Foundation, and the Whitaker Health Science Fund (A.M.G.); Neuroscience, Inc., MH 40303 (NIMH), MH 42068 (NIMH), CNS Research, Inc., Cambridge, Massachusetts (E.W.); and the Fondation pour la Recherche Medicale (M.-J.B.).

Correspondence should be addressed to Ann M. Graybiel, Ph.D., Professor of Neuroanatomy, Massachusetts Institute of Technology, Department of Brain and Cognitive Sciences, E25-618 45 Carleton Street, Cambridge, MA 02139

Copyright C 1989 Society for Neuroscience $0270-6474 / 89 / 010326-13 \$ 02.00 / 0$
}

(plus) isomer of SKF 10,047 and is now known to be related to the $N$-methyl-D-aspartate (NMDA) subtype of glutamate receptor; and a site with high affinity for (plus) SKF 10,047, which is now known as the sigma receptor (Largent et al., 1984, 1986; Tam and Cook, 1984; Zukin et al., 1984; Gundlach et al., 1985; Tam, 1985; Sircar et al., 1986).

This sigma receptor exhibits high affinity for the ncuroleptic drug haloperidol but does not bind dopamine (Largent et al., 1986; Weber et al., 1986a). It shows stereospecificity for SKF 10,047 and other benzomorphans and is thought to be responsible for some of the psychotomimetic effects of benzomorphans and related opiate drugs (Largent et al., 1986; Weber et al., 1986b). A number of phenothiazines are also active at sigma receptors. Most recently, sigma receptors have been implicated in the binding of steroids in the brain ( $\mathrm{Su}$ et al., 1988). Given these pharmacologic properties, there is considerable interest in learning about the mechanisms and sites of action of these haloperidol-sensitive receptors.

The first anatomic evidence for discrete localization of sites binding sigma ligands was obtained by Largent, Gundlach, and coworkers (Largent et al., 1984; Gundlach et al., 1985, 1986). They carried out autoradiographic surveys of guinea pig and rat brain with a synthetic sigma-selective radiolabeled piperidine derivative, 3-(2-hydroxyphenyl)- $N$-(1-propyl)piperidine ( ${ }^{3} \mathrm{H}-3$-PPP). More recently, a similar study was made in the guinea pig with a radiolabeled sigma-selective derivative of guanidine, 1,3,di-ortho-tolyl-guanidine ( $\left.{ }^{3} \mathrm{H}-\mathrm{DTG}\right)$ (McLean and Weber, 1988). Both radioligands were found to have broad binding distributions within the forebrain and hindbrain, but both also displayed enhanced binding in a subset of regions identified as parts of the limbic and motor systems. Of particular interest was evidence that these sigma ligands bind in the substantia nigra pars compacta (Largent et al., 1984; Gundlach et al., 1985, 1986) because the sigma ligand 3-PPP was known to have effects suggesting dopaminergic agonist activity (Hjorth et al., 1981, 1983; Arnt et al., 1983a, b; Clark et al., 1985).

In the study reported here, and briefly elsewhere (Graybiel et al., 1987a), we examined the distribution of sigma-selective ${ }^{3} \mathrm{H}-$ DTG binding in the nigrostriatal system in the cat. By carrying out the autoradiographic binding in this species, we could interpret the findings in relation to the subdivisions of the dopamine-containing A8-A9-A10 cell complex recently identified in the cat as having differential projections to the striosome and matrix subdivisions of the striatum (Jimenez-Castellanos and Graybiel, 1987). We were also able to take advantage of new 
observations on the differential distributions of D1- and D2selective dopamine receptor radioligands in the substantia nigra of this species (Beckstead, 1987; Richfield et al., 1987; Besson et al., 1988) to compare directly the distribution of sigma sites with the location of the dopamine-receptor binding subtypes. The results demonstrate intense sigma binding in the nigral cell complex but suggest that the highest sigma binding is restricted to a single part of the substantia nigra pars compacta. As this subdivision has a preferential pattern of nigrostriatal connectivity with striosomes and is characterized by a profile of low D1 binding and high D2 binding relative to neighboring parts of the nigral complex, our findings raise the possibility that sigma-mediated interactions with the dopaminergic nigrostriatal system may be highly selective at a functional level.

\section{Materials and Methods}

Tissue was obtained from the brains of 6 healthy adult cats without known pharmacologic treatments prior to induction of deep anesthesia with sodium pentobarbital (Nembutal). Brains were rapidly removed, and blocks containing the striatum and substantia nigra were frozen in pulverized dry ice and mounted on cryostat chucks. Coronal $15-\mu \mathrm{m}$ thick sections were thaw-mounted onto cold gelatin-coated slides and were collected in serial order. Sections taken at regular intervals were reserved for acetylcholinesterase (AChE) histochemistry (Geneser-Jensen and Blackstad, 1971; Jimenez-Castellanos and Graybiel, 1987) and tyrosine hydroxylase (TH) immunohistochemistry (Jimenez-Castellanos and Graybiel, 1987). All others were dried at $4^{\circ} \mathrm{C}$ under vacuum for $2-5 \mathrm{hr}$ and were then stored at $-20^{\circ} \mathrm{C}$ in slide boxes containing Drierite for at least 2 weeks before further processing (Lewis et al., 1982).

Ligand binding autoradiography. Series of sections chosen for binding were warmed and incubated (1) with ${ }^{3} \mathrm{H}-\mathrm{DTG}$ [synthesized as described by Weber et al. (1986a)] according to the protocol of McLean and Weber (1988) with slight modifications to demonstrate sigma binding sites; (2) with ${ }^{3} \mathrm{H}-\mathrm{SCH} 23390$ (New England Nuclear) by methods described for the cat by Besson et al. (1988) to demonstrate D1 binding sites; (3) with ${ }^{3} \mathrm{H}$-sulpiride (Amersham) according to Gehlert and Wamsley (1985), with slight modifications to demonstrate D2 binding sites; or (4) with ${ }^{3} \mathrm{H}$-naloxone according to Herkenham and Pert (1982) to demonstrate opiate binding sites. Sections were placed flat in plastic boxes lined with damp towels and $500 \mu \mathrm{l}$ of the preincubation and incubation solutions were applied successively to the sections. Washes were carried out in coplin jars. In every experiment controls for nonspecific binding were prepared in parallel with the series for specific binding.

For sigma binding, sections were preincubated for $5 \mathrm{~min}$ at $4^{\circ} \mathrm{C}$ in 50 $\mathrm{mm}$ Tris buffer ( $\mathrm{pH} 8.0$ ) containing $1 \mathrm{mg} / \mathrm{ml} \mathrm{BSA}$ and then were incubated for $45 \mathrm{~min}$ at room temperature in the same buffer solution containing $2.0 \mathrm{nM}$ (4 cats) or $30 \mathrm{~nm}\left(2\right.$ cats) ${ }^{3} \mathrm{II}-\mathrm{DTG}$. Two $5 \mathrm{~min}$ postincubation washes were carried out at $4^{\circ} \mathrm{C}$ in $10 \mathrm{~mm}$ Tris buffer $(\mathrm{pH}$ 7.4) containing $0.2 \mathrm{mg} / \mathrm{ml} \mathrm{BSA}$. Control sections were treated identically except that $10^{-5} \mathrm{M}$ haloperidol was added to the incubation solution. For D1-selective binding, incubations were carried out at room temperature for $60 \mathrm{~min}$ incubation in $2.5 \mathrm{nM}{ }^{3} \mathrm{H}-\mathrm{SCH} 23390$ in $50 \mathrm{~mm}$ Tris $\mathrm{HCl}$ buffer containing salts (Tris-salt buffer) as follows: $120 \mathrm{~mm} \mathrm{NaCl}$, $5 \mathrm{mM} \mathrm{KCl}, 2 \mathrm{mM} \mathrm{CaCl}$, and $1 \mathrm{~mm} \mathrm{MgCl}_{2}$. The buffer was brought to pH 7.4 with $10 \mathrm{~N} \mathrm{NaOH}$. Following incubation, sections were washed twice for $2 \mathrm{~min}$ in Tris-salt buffer. Nonspecific binding controls were incubated in the presence of $10^{-6} \mathrm{M}$ unlabeled SCH23390 (gift of Dr. R. Iorio). Incubations for D2 binding were carried out at room temperature in $20 \mathrm{~nm}{ }^{3} \mathrm{H}$-sulpiride in Tris-salt buffer containing $0.01 \%$ ascorbic acid, and sections were washed in the buffer twice for $2 \mathrm{~min}$. Control sections were incubated in the presence of $10^{-6} \mathrm{M}$ haloperidol.

Following incubation and washes in buffer, sections were dipped in distilled water and were dried under a stream of cold air, apposed to ${ }^{3} \mathrm{H}$-sensitive film (Amersham or LKB), and stored at room temperature in X-ray cassettes for time periods determined by trials ( $2.0 \mathrm{~nm}$ sigma, ca. 8 weeks; 30 nm sigma ca. 5 weeks; D1, ca. 3 weeks; D2, ca. 8 weeks) before being developed in Kodak D-19. Amersham ${ }^{3} \mathrm{H}$-microscale standards, as well as sections for nonspecific binding, were apposed to each of the films along with the sections for specific binding. For sigma binding, selected sections were exposed to formaldehyde vapors and then dipped in chloroform after incubation to test for the possibility that patterns of myelinization contributed to the binding patterns observed.

Binding curves. Curves for specific and nonspecific ${ }^{3} \mathrm{H}-\mathrm{DTG}$ binding were made on the basis of counts obtained from sections incubated according to the protocol followed for the autoradiography in ascending concentrations of ${ }^{3} \mathrm{H}$-DTG from 1.4 to $90 \mathrm{~nm}$. After being dried, the ventral halves of sections at levels through the substantia nigra, some containing attached pontine gray matter, were scraped off the slides into scintillation vials for counting or for estimates of protein content by the Lowry method (Lowry et al., 1951). With occasional exceptions, 4 sections for specific binding and 4 for nonspecific binding were processed for each concentration of ${ }^{3} \mathrm{H}-\mathrm{DTG}$ along with blanks in which tissue was omitted, and 4 sections were used for the Lowry assay. Average disintegrations per minute (dpm) were calculated for all binding conditions, and data were analyzed with RS/ 1 software. Total binding and nonspecific binding values were determined as averages of the multiple determinations, and specific binding was calculated as differences of these two. Values were expressed as $\mathrm{dpm} / \mathrm{mg}$ protein/section using the results of the Lowry assays. Total, specific, and nonspecific binding curves were plotted, Scatchard analysis was performed by linear regression, and $K_{a}$ and $B_{\max }$ were calculated with the RS/1 program.

Histochemistry and immunohistochemistry. In every case sections briefly postfixed in $0.1 \%$ glutaraldehyde in $0.1 \mathrm{M} \mathrm{PO}_{4}$ buffer were stained on-slide for AChE activity by a modified Geneser-Jensen and Blackstad method (1971), and other sections briefly postfixed in $0.1 \mathrm{M}$ phosphate buffer containing $4 \%$ paraformaldehyde were processed for TH-like immunoreactivity in neurons of the A8-A9-A 10 cell complex by methods described by Jimenez-Castellanos and Graybiel (1987). Antibodies to TH were purchased from Eugene Tech and were used at a dilution of $1: 250$ in a peroxidase-antiperoxidase immunohistochemical protocol with double bridge steps (Graybiel et al., 1987b). In most instances, sections incubated for ligand binding were stained for $\mathrm{AChE}$ after completion of the autoradiographic exposure period.

Anatomical analysis. Analysis of the autoradiograms and stained sections was mainly qualitative. Films were studied, photographed, and compared with other autoradiograms and to stained sections viewed with the aid of a macroprojector or microscope. Alignments of films and sections were made by matching blood vessels and other local landmarks.

Subdivisions of the A8-A9-A10 cell complex were identified according to the conventions described in Jimenez-Castellanos and Graybiel (1987). Within the substantia nigra pars compacta (cell group A9), a caudomedial zone of densely packed $\mathrm{TH}$-positive neurons corresponds to the densocellular zone. This region has fingerlike forward extensions that appear as cell nests in transverse TH-immunostained sections. The larger more lateral and anterior part of the substantia nigra's pars compacta containing loosely arranged TH-positive neurons corresponds to the cell-sparse zone of the pars compacta. The pars lateralis, also sparsely populated by TH-positive neurons, extends laterally from the cell-sparse zone. Cell group A8 (the retrorubral nucleus) forms a large dorsally and caudally situated zone. The borderline between the medially located ventral tegmental area (cell group A10) and cell groups A8 and A9 is not sharply drawn.

For identification of these subdivisions of the nigral complex we routinely relied on patterns of AChE staining visible in the same or adjacent sections. Particularly clear is the main part of the densocellular zone, which has lower AChE staining than adjoining regions (JimenezCastellanos and Graybiel, 1987). There is somewhat reduced AChE staining in the pars lateralis relative to that in the adjoining cell sparse zone and pars reticulata. Cell group A8 can usually be located by the appearance of heightened $\mathrm{AChE}$ activity in the neuropil dorsal to and intermingled amid the fibers of the medial lemniscus.

At striatal levels, striosomes were identified as ca. $0.5-\mathrm{mm}$-wide zones having characteristically reduced $\mathrm{AChE}$ staining relative to that in the surrounding matrix (Graybiel and Ragsdale, 1978).

Quantitative autoradiography. A limited series of sections was analyzed by quantitative densitometric methods with the aid of a computerassisted device (Imstar). Quantitative estimates of ligand binding were made by measuring the optical density in particular regions of interest. In some instances, a profile of optical density was made along traverses across the autoradiographic images of the sections (see Fig. 3). Optical densities given by the ${ }^{3} \mathrm{H}$-microscale Amersham standards were first measured, and a regression curve was drawn to obtain the correspondence between optical density and radioactivity in $\mu \mathrm{Ci} / \mathrm{mg}$ of tissue. The optical densities were then converted to femtomoles of bound ligand according to the specific activity of the tritiated ligand used. 

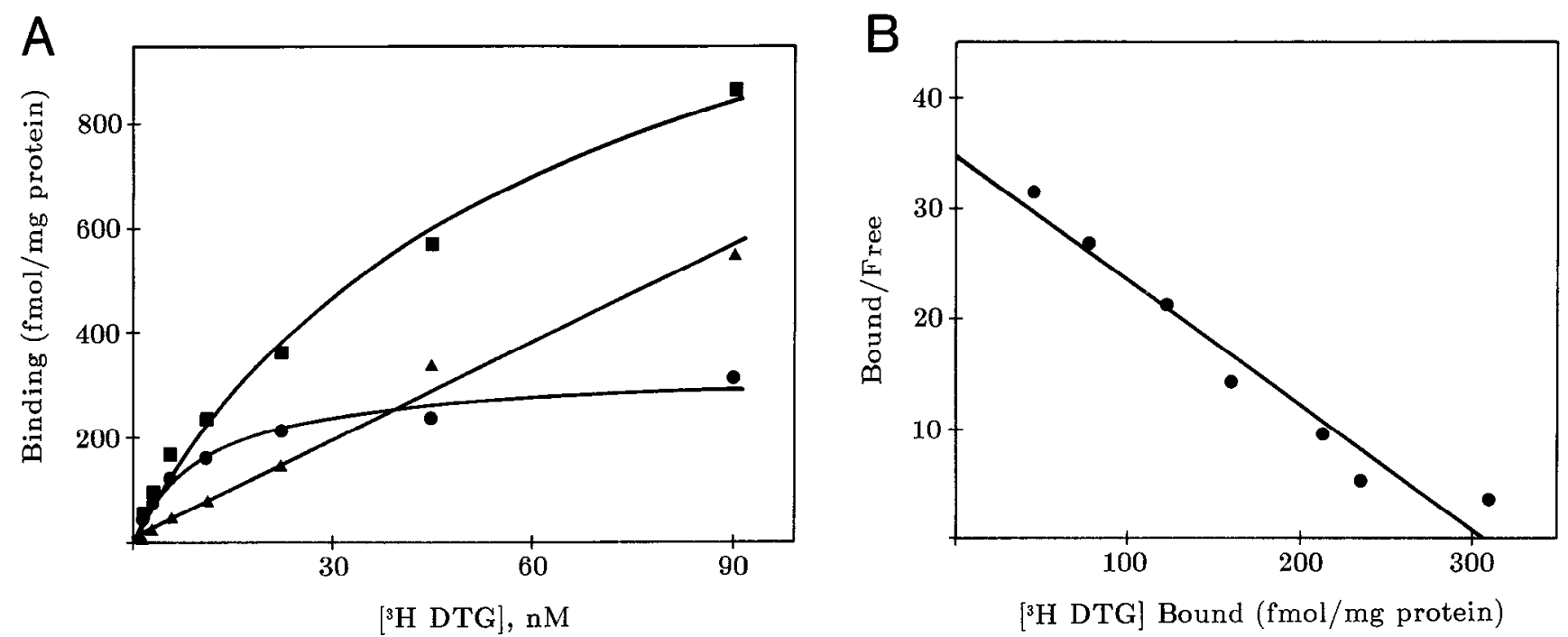

Figure 1. Binding curves $(A)$ and Scatchard analysis $(B)$ of ${ }^{3} \mathrm{H}-\mathrm{DTG}$ binding in the ventral midbrain of the cat (case CDAR-9). Squares, total binding; triangles, nonspecific binding (in presence of $10^{-5} \mathrm{M}$ haloperidol); filled circles, specific binding.

\section{Results}

\section{${ }^{3} H$-DTG binding characteristics}

The measurements made from sections through the ventral midbrain suggested that the binding of ${ }^{3} \mathrm{H}-\mathrm{DTG}$ had a specific component that was saturable and that had an apparent $K_{d}$ of 8.85 nM and an apparent $B_{\max }$ of $306.5 \mathrm{fmol} / \mathrm{mg}$ protein (Fig. $1 A$ ). Nonspecific binding increased lincarly but sharply with increasing concentrations of ${ }^{3} \mathrm{H}-\mathrm{DTG}$. The nonspecific component comprised $18 \%$ of the total at $1.4 \mathrm{nM}{ }^{3} \mathrm{H}-\mathrm{DTG}$ and $27 \%$ at 2.9 nM ${ }^{3} \mathrm{H}$-DTG, concentrations bracketing the 2 nм standard incubation concentration for the autoradiographic work. Nonspecific binding was nearly $40 \%$ at the estimated $K_{d .}$. The results of Scatchard analysis were compatible with binding to a single site (Fig. $1 B$ ).

By autoradiographic analysis, moderate levels of ${ }^{3} \mathrm{H}-\mathrm{DTG}$ binding appeared in much of the gray matter, and binding was very low in white matter (Fig. 2). Intense binding was present in the choroid plexus, and heightened binding appeared in a subset of regions of the forebrain and brain stem, including many as reported previously for the guinea pig and rat: for example, motor nuclei of the cranial nerves, the hippocampal formation, anterior and midline-intralaminar thalamus, and pontine nuclei (Gundlach et al., 1986; McLcan and Weber, 1988). Perceptible binding was nil in sections incubated in the presence of $10^{-5} \mathrm{M}$ haloperidol, as shown in Figure 2, $A, A^{\prime}$. At 30 nм ${ }^{3} \mathrm{H}-\mathrm{DTG}$, the highest concentration of ligand used in test experiments, binding was nearly abolished by $10^{-5} \mathrm{M}$ haloperidol as well (Fig. $\left.2, B, B^{\prime}\right)$. Binding patterns were not eliminated by defatting to abolish quenching by myelinated fibers (Fig. 2, $C, C^{\prime}$ ).

\section{${ }^{3} H$-DTG binding in the $A 8-A 9-A 10$ cell complex}

Dense binding appeared in the substantia nigra pars compacta in a discretely localized medial and caudal part of this nigral subdivision. As illustrated in Figure 3, comparison of the autoradiographic films and the AChE staining in serially adjacent sections indicated a close spatial match between the region of heightened ligand binding and the zone of low AChE activity identifiable as the densocellular zone of the substantia nigra pars compacta. For example, on the left side of the sections a patch of heightened binding at the lateral edge of the grain-dense band matches a lateral patch of low $\mathrm{AChE}$ activity. Also recognizable in the AChE-stained section of Figure $3 B$ are the cell-sparse part of the substantia nigra's pars compacta and the pars reticulata, both of which are heavily stained; the pars lateralis, which has relatively reduced $\mathrm{AChE}$ staining; and the rostral part of the $\mathrm{A} 8$ cell group, identifiable by a dorsal extension of AChE-positive neuropil above the level of the substantia nigra proper. None of these nigral subdivisions shows particularly intense ${ }^{3} \mathrm{H}-\mathrm{DTG}$ binding. The binding in cell group $A 8$ is greater than that in the immediately adjoining reticular formation, but relative to the densocellular zone (or to other intensely labeled regions such as the central gray substance), the binding is not marked. Finally, binding is weak in most of the ventral tegmental area, in sharp contrast to the intense binding in the adjoining interpeduncular nucleus. Just dorsal to the interpeduncular nucleus, however, in a region apparently corresponding to the interfascicular nucleus, sigma binding is quite dense.

Figure $3 C$ shows densitometric measurements made for the ${ }^{3} \mathrm{H}$-DTG binding illustrated photographically in Figure 3. A traverse was made across the ventral midbrain so that relative densities could be shown for the substantia nigra pars reticulata and pars compacta, and for the median and paramedian structures in and around the interpeduncular nucleus. The ${ }^{3} \mathrm{H}-\mathrm{DTG}$ binding was higher in the pars compacta's densocellular zone than in any of the neighboring structures. Taking the binding levels in the densocellular zone to be $100 \%$, the values from a series of 7 such passes are as follows: substantia nigra pars reticulata, $45 \%$; cell group $\mathrm{A} 8,40 \%$; ventral tegmental region, $30 \%$; and interpeduncular nucleus, $65 \%$.

More rostral and caudal levels through the nigral complex are shown in Figure 4. In the rostral part of the substantia nigra, ${ }^{3} \mathrm{H}$-DTG labeling was nearly homogeneously distributed. It was not possible, for example, from the sigma autoradiograms alone to discriminate between the pars compacta and the pars reticulata. In Figure $4 A$, a region of slightly enhanced binding in the medial part of the substantia nigra immediately beside the exiting rootlets of the oculomotor nerve and a pocket of slightly 

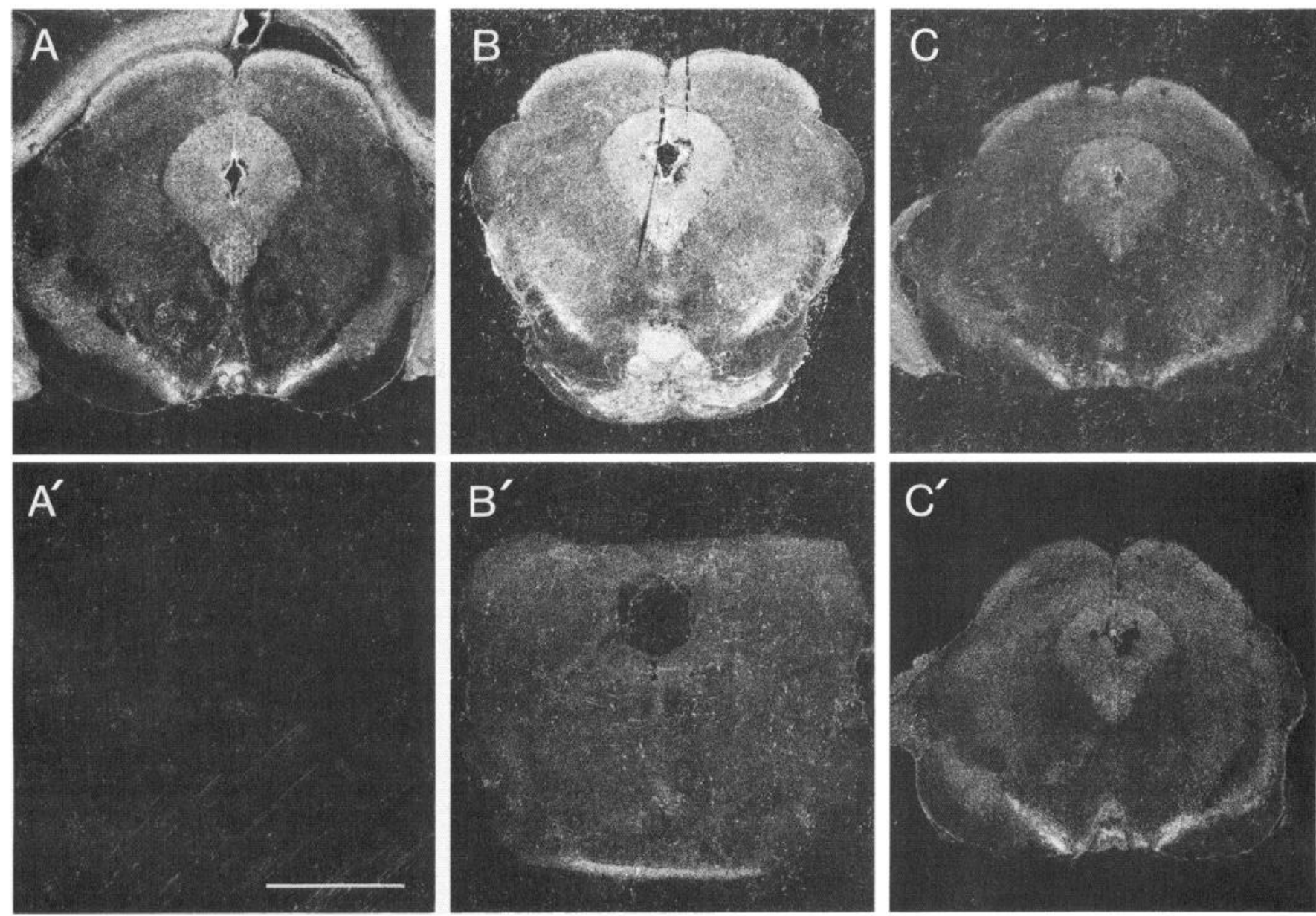

Figure 2. Autoradiographic analysis of ${ }^{3} \mathrm{H}$-DTG binding under different experimental $(A-C)$ and control $\left(A^{\prime}-C^{\prime}\right)$ conditions. Each pair of sections was treated in parallel and exposed on the same film. For sections shown in $A$ and $A^{\prime}$ (from CDAR-6), binding was carried out in $2.0 \mathrm{nM}{ }^{3} \mathrm{H}-\mathrm{DTG}$; for $A^{\prime}, 10^{-5} \mathrm{M}$ haloperidol was added to the incubation solution. Sections shown in $B$ and $B^{\prime}$ (from CDAR-9) were incubated in $30 \mathrm{nM}{ }^{3} \mathrm{H}-\mathrm{DTG}$ with $\left(B^{\prime}\right)$ or without $10^{-5} \mathrm{M}$ haloperidol. Sections in $C$ and $C^{\prime}\left(\right.$ from CDAR-7) were treated similarly except that section $C^{\prime}$ was defatted after incubation and drying. Scale bar, $5 \mathrm{~mm}$ for all panels.

enhanced binding corresponding to the rostral pole of cell group A8 give the only hints of preferential labeling within the complex. In fact, binding was higher along the dorsolateral corner of the substantia nigra, in the region of the peripeduncular nucleus, than in the immediately adjoining substantia nigra. The peripeduncular nucleus, distinguished by affiliations with the amygdala (Mehler, 1980) and by differentially high somatostatin-like immunoreactivity (Graybiel and Elde, 1983), is not considered to form part of the nigral complex.

There was a sharp contrast between the high levels of ${ }^{3} \mathrm{H}$ DTG binding in the substantia nigra's densocellular zone and the low levels of binding in the ventral tegmental area adjoining it medially. In the interpeduncular nucleus, however, binding was intense; and along the dorsal rim of the interpeduncular nucleus, corresponding apparently to the nucleus interfascicularis and foyer pedunculaire of the central linear nucleus (Berman, 1968; Phillipson, 1979; Swanson, 1982; Poirier et al., 1983), binding was also enhanced.

At the more caudal levels shown in Figure 4, $B, C$, the densocellular zone of the substantia nigra is present and can be as readily recognized by the intense ${ }^{3} \mathrm{H}-\mathrm{DTG}$ binding there as by its low AChE staining. Some binding is visible also in more lateral parts of the substantia nigra and in cell group A8, which forms a prominent dorsal cap overlying the caudal part of the substantia nigra. These binding levels, however, do not approach the high levels characteristic of the densocellular zone.

A closely similar pattern of selectively dense ${ }^{3} \mathrm{H}$-DTG binding in the densocellular zone appeared in each brain examined. This was true for sections incubated in $30 \mathrm{~nm}^{3} \mathrm{H}-\mathrm{DTG}$ (Fig. $2 B^{\prime}$ ) and for sections that were defatted following incubation and drying (Fig. $2 C^{\prime}$ ).

Comparisons of sigma-selective ${ }^{3} \mathrm{H}-\mathrm{DTG}$ binding with DI and D2 dopamine receptor-selective binding and with mu opiate receptor-selective binding

The autoradiograms of Figure 5 illustrate the disposition of ${ }^{3} \mathrm{H}-$ DTG binding in the nigral complex in relation to ${ }^{3} \mathrm{H}-\mathrm{SCH} 23390$, ${ }^{3} \mathrm{H}$-sulpiride, and ${ }^{3} \mathrm{H}$-naloxone binding.

The 2 dopamine receptor-related ligands have markedly different distributions in relation to the sigma binding. There is partial, if not full, complementarity between the strong ${ }^{3} \mathrm{H}$-DTG labeling of the densocellular zone (Fig. $5 \mathrm{~A}$ ) and low D1-related ${ }^{3} \mathrm{H}-\mathrm{SCH} 23390$ binding there (Fig. $5 B$ ). By contrast, there is a close alignment between the zone of heightened ${ }^{3} \mathrm{H}-\mathrm{DTG}$ binding in the medial part of the substantia nigra pars compacta and the zone of slightly heightened D2-related ${ }^{3} \mathrm{H}$-sulpiride binding 

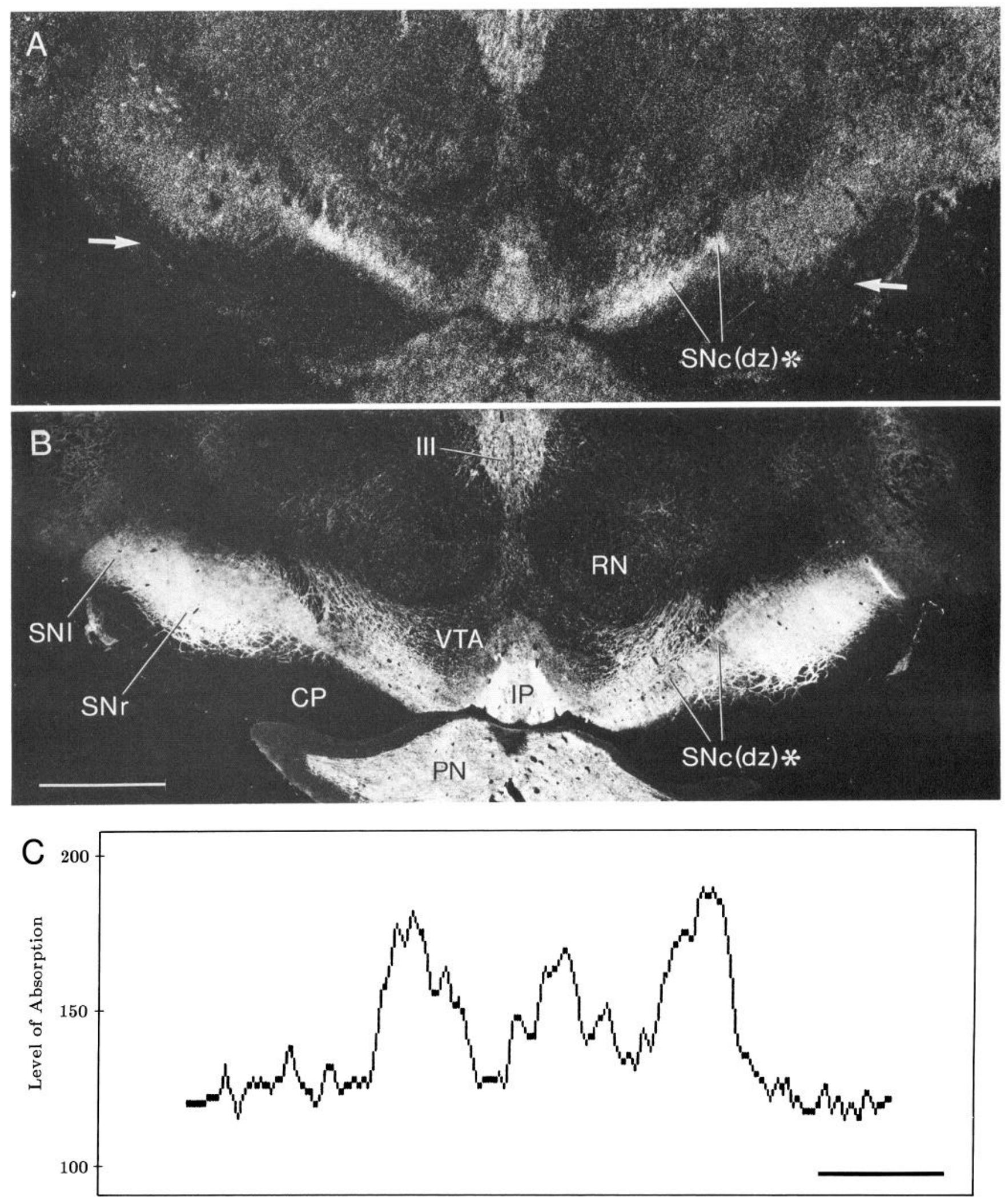

Figure 3. Photographs of ${ }^{3} \mathrm{H}-\mathrm{DTG}$ autoradiogram $(A)$ and nearly adjoining AChE-stained section $(B)$ from case CDAR-8 illustrating sigma binding in the nigral complex and ventral tegmental region. In the nigral complex, dense binding is confined to the densocellular zone of the substantia nigra's pars compacta $\left[S N c(d z)^{*}\right]$, identifiable in the companion AChE-stained section as a region of weak staining. Note detailed match of the AChE-poor zone and the zone of enhanced ${ }^{3} \mathrm{H}$-DTG binding, especially clear on right side. In paramedian tegmentum, note heightened ${ }^{3} \mathrm{H}-\mathrm{DTG}$ binding in the interpeduncular nucleus $(I P)$ and above it in the interfascicular nucleus and central linear nucleus, including its "foyer pedunculaire" (Berman, 1968; Phillipson, 1979; Swanson, 1982; Poirier et al., 1983); and the weaker binding in the rostral linear nucleus and in the remainder of the ventral tegmental region (these regions are identified as such in Fig. 4). $C$, Plot of the level of absorption measured by computer-assisted densitometry along a traverse through the nigral complex at the level indicated by the arrows in $A$. The scales of $A$ and $C$ are adjusted so that 
there (Fig. $5 D$ ). Only the ${ }^{3} \mathrm{H}-\mathrm{SCH} 23390$ binding is relatively intense in the pars reticulata. The opioid ligand ${ }^{3} \mathrm{H}$-naloxone showed a slightly enhanced binding in the region just ventral to the densocellular zone; in this respect, it resembles the D1related ${ }^{3} \mathrm{H}-\mathrm{SCH} 23390$ binding, but binding in the remaining pars reticulata is lacking. The weak ${ }^{3} \mathrm{H}$-naloxone binding in the nigral complex was not a consequence of generalized low levels of binding for this ligand, as shown in Figure $5 E$ by the intense binding in the immediately adjoining interpeduncular nucleus.

Table 1 shows the quantitative estimates of ${ }^{3} \mathrm{H}-\mathrm{DTG},{ }^{3} \mathrm{H}$ $\mathrm{SCH} 23390,{ }^{3} \mathrm{H}$-sulpiride, and ${ }^{3} \mathrm{H}$-naloxone binding for the same sections as those shown in the photographs of Figure 6. The differences in relative labeling of individual cell groups of the nigral complex confirm the visual impression of differential binding given by the autoradiograms: ${ }^{3} \mathrm{H}$-DTG binding in the nigral complex was densest in the densocellular zone; ${ }^{3} \mathrm{H}$-sulpiride binding though generally very weak was also densest there; but ${ }^{3} \mathrm{H}-\mathrm{SCH} 23390$ binding and ${ }^{3} \mathrm{H}$-naloxone binding were relatively weaker in the densocellular zone. Only ${ }^{3} \mathrm{H}$-naloxone bound strongly to the interpeduncular nucleus, but ${ }^{3} \mathrm{H}-\mathrm{DTG}$ binding was appreciable there and also in the interfascicular nucleus and rostral raphe complex, including the central and rostral linear nuclei.

\section{Location of ${ }^{3} \mathrm{H}-\mathrm{DTG}$ binding in the striatum}

${ }^{3} \mathrm{H}$-DTG binding was moderate in all parts of the striatum. As shown in Figure 6, apparent levels of labeling in the caudate nucleus, putamen, and nucleus accumbens were similar, as judged by the films, and there was almost no hint of local compartmental ordering. Very rarely, zones of slightly reduced binding appeared in the dorsocaudal part of the caudate nucleus. These zones did not appear to correspond to striosomes, as indicated by their lower ${ }^{3} \mathrm{H}$-sulpiride labeling, heightened ${ }^{3} \mathrm{H}-\mathrm{SCH} 23390$ binding, or low AChE activity.

\section{Discussion}

The cardinal finding of this study is that the sigma-specific ligand ${ }^{3} \mathrm{H}$-DTG displays focally intense binding in the densocellular zone of the substantia nigra pars compacta. The potential significance of this finding lies in evidence, presented here and in previous reports (Jimenez-Castellanos and Graybiel, 1987; Besson et al., 1988), that this zone is both pharmacologically distinct in terms of the intranigral distribution of other neurotransmitter-related compounds, including dopamine receptor-related ligands, and connectionally distinct in terms of the apparent preferential linkage of this sigma-rich subdivision with the striosomal labyrinths of the striatum. This anatomical specificity raises the possibility that some of the functional effects of sigma-ligands may be similarly focused. If so, they may act selectively on a subset of the dopaminergic pathways now known to interconnect the midbrain and striatum.

\section{Binding characteristics and Scatchard analysis}

The selective pattern of ${ }^{3} \mathrm{H}-\mathrm{DTG}$ labeling reported here was seen under binding conditions in which ligand binding was saturable and had a high specific (haloperidol-sensitive) component. The heightened labeling of the densocellular zone was
Table 1. Evaluation of the binding sites for ${ }^{3} \mathrm{H}-\mathrm{DTG},{ }^{3} \mathrm{H}-$-naloxone, ${ }^{3} \mathrm{H}$-sulpiride, and ${ }^{3} \mathrm{H}-\mathrm{SCH} 23390$ at the level of the ventral mesencephalon

\begin{tabular}{|c|c|c|c|c|}
\hline Parameter & ${ }^{3} \mathrm{H}-\mathrm{DTG}$ & $\begin{array}{l}{ }^{3} \mathrm{H}- \\
\text { SCH- } \\
23390\end{array}$ & $\begin{array}{l}{ }^{3} \mathrm{H}-\mathrm{Sul}- \\
\text { piride }\end{array}$ & $\begin{array}{l}{ }^{3} \mathrm{H}-\mathrm{Nal}- \\
\text { oxone }\end{array}$ \\
\hline Specific activity $(\mathrm{Ci} / \mathrm{mmol})$ & 52 & 77 & 60 & 40 \\
\hline$[$ Ligand] $(\mathrm{nm})$ & 2 & 2.5 & 20 & 2.5 \\
\hline \multirow[t]{2}{*}{$K_{d}(\mathrm{nM})$} & 8.85 & 1.9 & 11.2 & 2.5 \\
\hline & \multicolumn{4}{|c|}{ Binding (fmol/mg tissue) } \\
\hline Structure & $477^{a}$ & 481 & 476 & 478 \\
\hline $\mathrm{SNc}(\mathrm{dz})$ & 95 & $0^{h}$ & 28 & $0^{b}$ \\
\hline A8 & 50 & 63 & 18 & 45 \\
\hline $\mathrm{SNr}$ & 35 & 153 & 14 & 29 \\
\hline Interpeduncular nucleus & 67 & 13 & 16 & 340 \\
\hline
\end{tabular}

Binding studies were performed on adjacent sections for ${ }^{3} \mathrm{H}-\mathrm{DTG},{ }^{3} \mathrm{H}$-naloxone, ${ }^{3} \mathrm{H}$-sulpiride, and, on a nearby section, ${ }^{3} \mathrm{H}-\mathrm{SCH} 23390$. Specific activity of ligands, as well as the concentration used for the binding evaluation, are indicated in the upper section. For comparison, the $K_{d}$ values obtained from binding curves calculated on the basis of values from cat brain sections incubated with various concentrations of 'H-DTG (present results) or 'H-SCH23390 (see Besson et al., 1988) and the $K_{i d}$ values of ${ }^{3} \mathrm{H}$-naloxone and ${ }^{3} \mathrm{H}$-sulpiride published for rat brain slices (Herkenham and Pert, 1982; Gehlert and Wamsley, 1985) are reported in the table. In the lower section, values correspond to binding sites expressed in frnoles/nig tissue. Mean values were obtained from densitometric measurements made on the left and right sides of homologous structures corresponding to $\mathrm{SNc}(\mathrm{dz}), \mathrm{A8}, \mathrm{SNr}$, and the interpeduncular nucleus. In the $\mathrm{SNc}(\mathrm{dz}),{ }^{3} \mathrm{H}$-naloxone and ${ }^{3} \mathrm{H}-\mathrm{SCH} 23390 \mathrm{binding}$ was below measurable levels. Values for the 2 sides did not vary more than \pm 5 . From the ${ }^{3} \mathrm{H}$-DTG binding curve, we calculated, by interpolation, the values that would correspond to the number of binding sites at an incubation concentration corresponding to the $K_{i}$ as follows: $\mathrm{SNc}(\mathrm{dz}), 287 ; \mathrm{A8}, 152 ; \mathrm{SNr}, 120 ;$ interpeduncular nucleus, 205.

"Section number.

"Binding below measurable levels.

observed in every animal studied, and it was visible in sections that had been defatted to test for the possibility that the patterning of myelinization in the tissue could account for the distributions observed (Joyce et al., 1986). Further, in the same brains, different patterns of binding were observed in the nigral complex with other radioligands, so that the pattern of sigma binding was not a general one for ligand binding in the region. We conclude that the ${ }^{3} \mathrm{H}$-DTG binding observed was specifically attributable to sigma binding sites as defined in previous studies with this ligand (Weber et al., 1986a; McLean and Weber, 1988).

Scatchard plots were linear, suggesting a single binding site for the ${ }^{3} \mathrm{H}$-DTG with a $B_{\max }$ of $306 \mathrm{fmol} / \mathrm{mg}$ protein and a $K_{d}$ of $8.85 \mathrm{~nm}$ for tissue sections blocked down to the ventral midbrain/pons and scraped from slides following incubation. The corresponding values for whole guinea pig brain sections have been reported as $B_{\max }=573 \mathrm{fmol} / \mathrm{section}$ and $K_{d}=133 \mathrm{~nm}$ (McLean and Weber, 1988). We have no explanation for the difference in values obtained here, but measurements on tissue homogenates suggest variations in $B_{\max }$ and $K_{d}$ values both among different brain regions and among different species (Sonders et al., 1987; $\mathrm{Vu}$ et al., 1987). Differences between the values obtained from whole-brain homogenates and those from tissuc sections from the same species have also been found (Weber et 

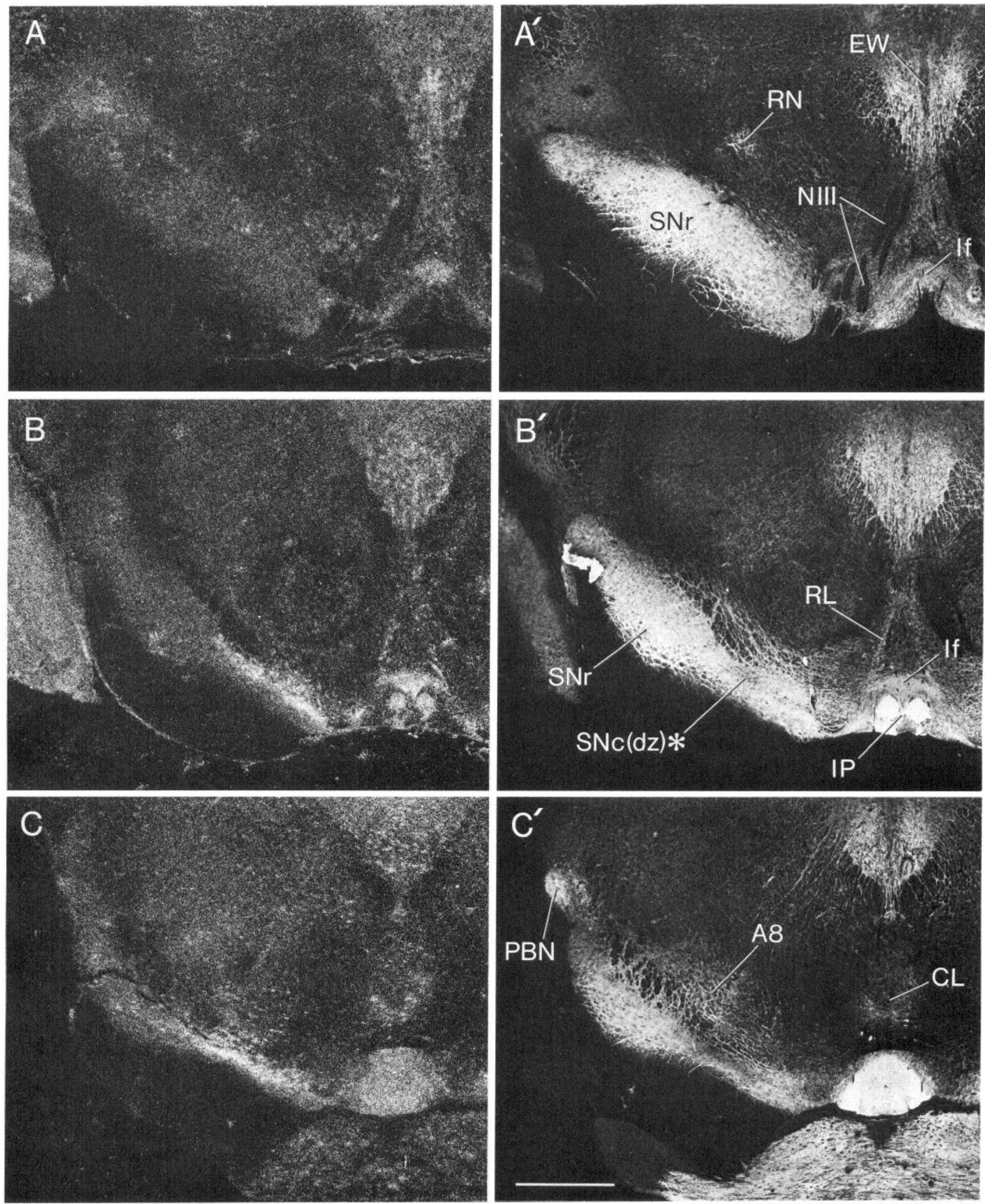

Figure 4. Rostral $\left(A, A^{\prime}\right)$, middle $\left(B, B^{\prime}\right)$, and caudal $\left(C, C^{\prime}\right)$ transverse levels through the nigral complex illustrating ${ }^{3} \mathrm{H}-\mathrm{DTG}$ binding $(A-C)$ and AChE staining $\left(A^{\prime}-C^{\prime}\right)$ in sections from CDAR-6 that were first processed for ${ }^{3} \mathrm{H}$-DTG binding and then stained for AChE. The 3 sets of photographs were carefully aligned so that details of the binding distributions can be compared with the AChE staining patterns. Note that dense nigral ${ }^{3} \mathrm{H}$ DTG binding is coextensive with densocellular zone. $E W$, Edinger-Westphal nucleus (which shows heightened binding); $R N$, red nucleus; $S N r$, substantia nigra pars reticulata; $S N c(d z)^{*}$, densocellular zone of substantia nigra pars compacta; $N I I I$, rootlets of oculomotor nerve; $I P$, interpeduncular nucleus; $R L$, rostral linear nucleus; $C L$, central linear nucleus; $P B N$, parabigeminal nucleus; $A 8$, catecholaminergic cell group A8. Note heightened sigma binding in the interfascicular nucleus (If) dorsal to IP and weaker but appreciable binding in the rostral raphe complex. Scale bar, $2 \mathrm{~mm}$. 
al., 1986a). For example, in homogenates of guinea pig brain, $K_{d}=28 \mathrm{nM}$; in guinea pig sections, $K_{d}=133 \mathrm{nM}$ (McLean and Weber, 1988); and in cerebellar homogenates, $K_{d}=27 \mathrm{~nm}$ in guinea pig but $57 \mathrm{~nm}$ in human (Sonders et al., 1987). In the experiments reported here, we attempted to obtain $K_{d}$ and $B_{\max }$ values characteristics of nigral tissue by collecting only the ventral parts of sections through the midbrain levels containing the substantia nigra. The values obtained cannot be taken as spccific for the nigral complex, however, because the region scraped from the slides was larger than the nigral complex proper and included such sites of high binding as the interpeduncular nucleus and part of the pontine gray matter. Relative to the autoradiographic findings on ${ }^{3} \mathrm{H}-\mathrm{DTG}$ binding in the guinea pig (McLean and Weber, 1988), the nonspecific binding in our experiments was high, about $20 \%$ at the standard incubation concentration. This background may have led to a masking of autoradiographic signals of specific binding, but this seems unlikely because the control sections incubated with $10^{-5} \mathrm{M}$ haloperidol had only the slightest perceptible binding. Further, background was not so high as to obscure borders between regions with major differences in binding density, such as shown for the substantia nigra, nor to blur the punctate "cellular" appearance of the autoradiographic binding in some districts, for example, in nuclei of the somatic motor column and in the red nucleus, characteristic also of the binding in rat and guinea pig (Gundlach et al., 1986; McLean and Weber, 1988).

\section{Interpretation of the autoradiographic patterns}

Four immediate questions challenge functional interpretation of autoradiographic binding site distributions: (1) Are the binding sites localized actually functional receptors? (2) Do the distributions accurately reflect the distribution of an endogenously active transmitter substance? (3) Do the sites localized represent. steady-state patterns of receptor (and ligand) binding? (4) Do the sites have particular subcellular distributions indicative of their biologic action? There are no sure answers to these questions for any class of binding site yet studied in mammalian brain. For the sigma sites we analyzed here, interpretation is especially difficult because powerful physiological and psychological effects have been attributed to these sites on the basis of drug studies, but endogenous ligands have not been identified with certainty. Despite these limitations, functional studies of a number of ligands have suggested that the distribution of binding sites can offer valuable clues to identifying functionally distinct neurotransmitter-related subsystems in the brain. Our findings with ${ }^{3} \mathrm{H}-\mathrm{DTG}$ suggest that in the nigrostriatal pathway at least one such subsystem may be defined by its prefcrential association with haloperidol-sensitive sigma binding sites.

Two lines of evidence on the physiological effects of sigmapreferring ligands are directly pertinent to the nigral binding patterns we have observed. First, the application of sigma-selective ligands to in vitro preparations of mouse (Campbell et al., 1987) and guinea pig (Vaupel and Su, 1987) vas deferens has been shown to enhance electrically evoked activity, and this effect has been found in the mouse preparations (Campbell et al., 1987) to be accompanied by increased release of norepinephrine. Thus, in a classic bioassay system, sigma-selective ligands modulate catecholamine release. It seems justifiable to propose, given the selective pattern of binding found here, that sigma-selective ligands might act analogously on dopamine release from the substantia nigra. This proposal continues an extensive second series of studies (e.g., see Hjorth et al., 1981,
1983, 1985; Arnt et al., 1983a, b; Clark et al., 1985) exploring the possible interactions of 3-PPP and related agents on dopaminergic functions, as discussed further below. Interestingly, an ionic mechanism that could underlie nonagonist effects on transmitter release has recently been proposed for the PCP receptor. In synaptosomal preparations, SKF 10,047 and PCP are reported to block a nonactivating voltage-sensitive potassium channcl, an action compatible with prolongation of the action potential and increase of transmitter release. No comparable evidence is yet available for the actions of DTG either in the periphery or CNS.

Second, experiments in the rat point to the cell bodies (or dendrites) of dopamine-containing nigrostriatal neurons as the sites of at least part of the sigma binding found in the substantia nigra: intrastriatal injection of the neurotoxin 6-hydroxydopamine (6-OHDA) destroys over $30 \%$ of nigral ${ }^{3} \mathrm{H}-3$-PPP binding at 2 week survival times (Gundlach et al., 1986). Our findings in the cat are compatible with such a cellular localization.

The single region of heightened ${ }^{3} \mathrm{H}-\mathrm{DTG}$ binding in the feline substantia nigra is precisely the zone with the highest density of cell bodies in the entire A8-A9-A10 complex. The differentially high levels of binding in the densocellular zone could thus reflect a larger number of sigma receptor-bearing cells in this zone rather than a greater number of sigma sites per neuron there. Now that the DTG-binding subunit of the sigma receptor has been isolated (Kavanaugh et al., 1987), it may soon be possible to approach this question with receptor-immunohistochemical methods. Either alternative, however, would lead to the prediction of a greater effect of sigma-selective drugs on the densocellular zone than on other parts of the nigral complex.

\section{Possible functional implications}

Many of the psychotomimetic and antipsychotic compounds that act at sigma sites have actions that are suggestive of effects on dopamine-containing neurons and their targets. In fact, some of the effects of 3-PPP are very similar to the effects of dopamine autoreceptor agonists (Hjorth et al., 1981, 1983, 1985; Arnt et al., 1983a, b; Clark et al. 1985). The fact that some classes of drugs have dual affinities for dopamine receptor and sigma receptors has greatly complicated interpretation of these response characteristics. The premiere example is the antipsychotic drug haloperidol, which is a dopamine D2 receptor blocker but has a definitionally high affinity for the sigma receptor ( $\mathrm{Su}, 1982$; Tam and Cook, 1984). The effects of haloperidol and related drugs clearly may be related to their actions at both sites; but sorting out such differential actions has been difficult (Hjorth et al., 1985).

The present findings add evidence that may be crucial in efforts to understand what links there are between sigma receptor-mediated and dopamine receptor-mediated effects in the nigrostriatal system. The fact that sigma-specific ligand binding in the substantia nigra is densest in an anatomically discrete part of the substantia nigra pars compacta, at least in the cat, means that sigma-selective ligands may, in part, affect dopamine receptors indirectly by altering the functional properties of this set of dopamine-containing neurons. We further found that the site of densest sigma-ligand binding in the nigral complex is also the site of densest D2-selective ligand binding. There is no cross-reactivity between ${ }^{3} \mathrm{H}-\mathrm{DTG}$ and dopamine receptor-related binding sites at any ${ }^{3} \mathrm{H}-\mathrm{DTG}$ concentration (Weber et al., 1986a). Thus, a drug such as haloperidol, by binding both at sigma sites and at D2 sites in the densocellular zone, may have 

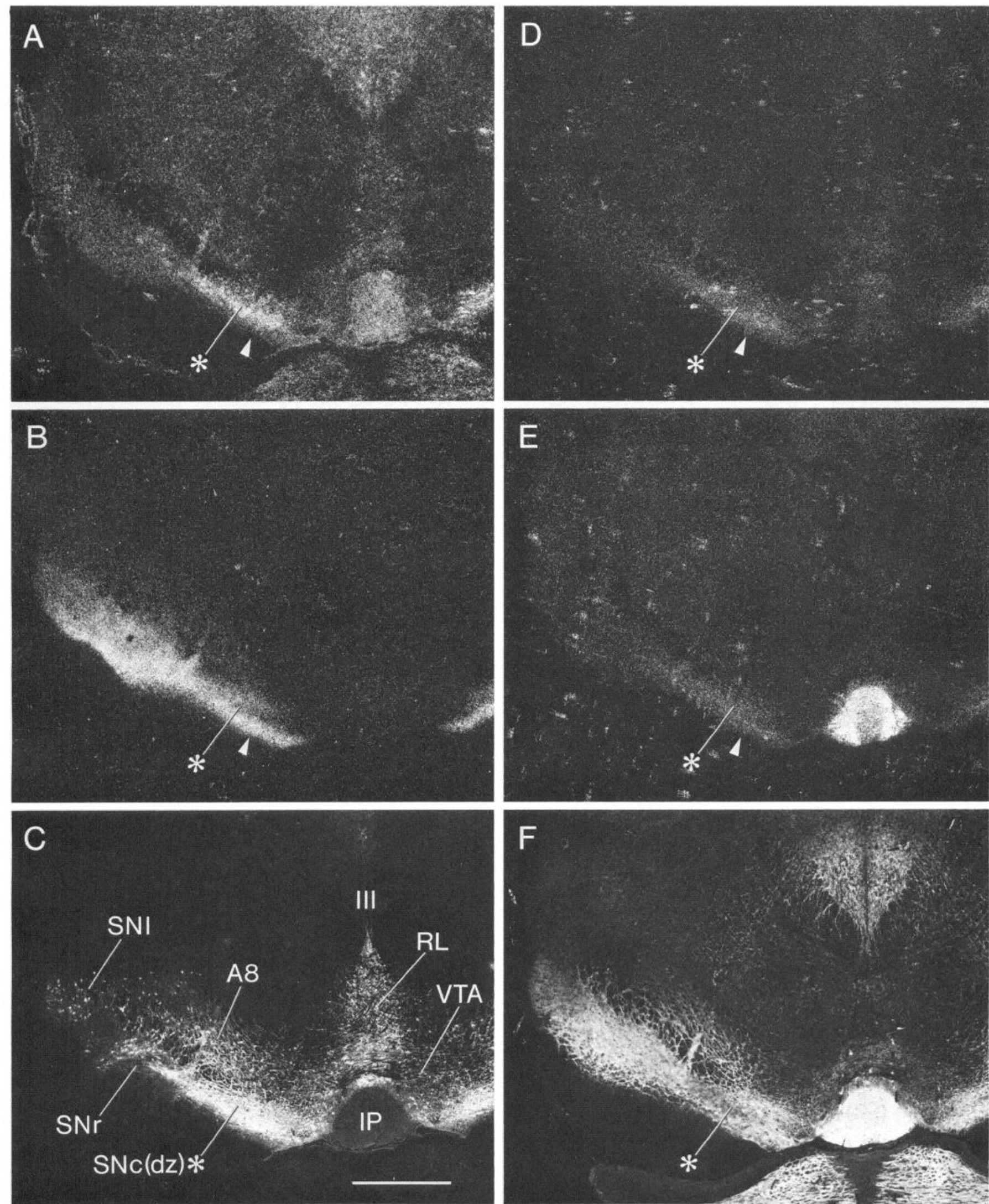

Figure 5. Autoradiographic demonstration of ${ }^{3} \mathrm{H}-\mathrm{DTG}$ sigma binding $(A)$ in localized parts of the dopamine-containing cell groups of the midbrain in comparison with $(B)$ dopamine D1 receptor-related binding of ${ }^{3} \mathrm{H}-\mathrm{SCH} 23390,(D)$ dopamine D2 receptor-related binding of ${ }^{3} \mathrm{H}$-sulpiride, and $(E)$ opiate receptor-related binding of ${ }^{3} \mathrm{H}$-naloxone. The sections are from case CDAR-6 and are nearly serial to each other and to the section shown in $C$, which was stained for TH-like immunoreactivity to indicate the locations of catecholaminergic neurons. $F$, Photograph of the same section shown in $D$ stained for $\mathrm{AChE}$ activity following processing for ${ }^{3} \mathrm{H}$-naloxone binding. The actual section sequence and spacings are: $C$ - $A$ - 

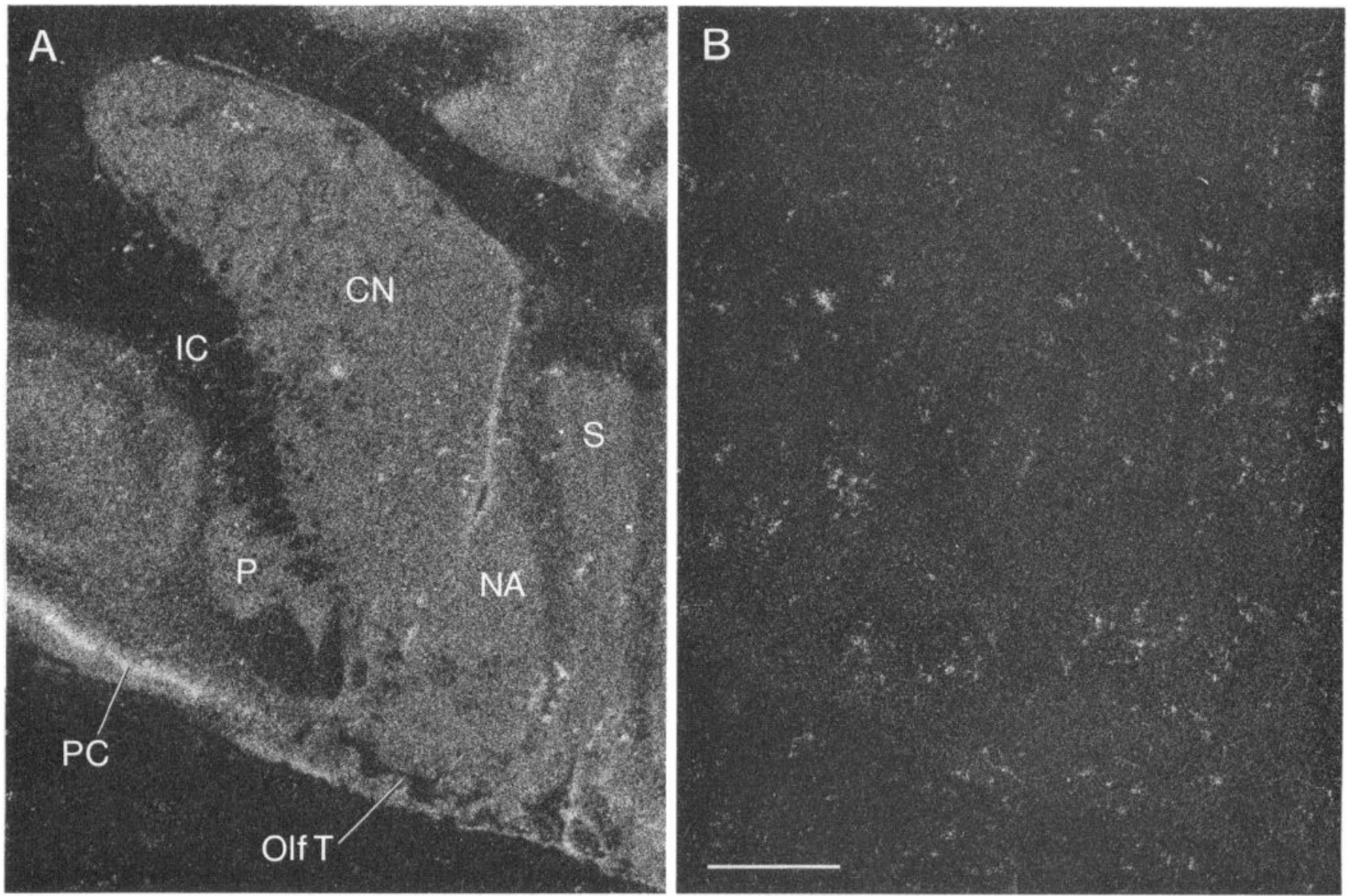

Figure 6. Specific $(A)$ and non-specific $(B){ }^{3} \mathrm{H}-\mathrm{DTG}$ binding in the striatum and adjoining regions in near-serial sections from case CDAR-6. $C N$, caudate nucleus; $P$, putamen; $N A$, nucleus accumbens; $I C$, internal capsule; $O l f T$, olfactory tubercle; $S$, septum; $P C$, piriform cortex (with dense band of labeling). Scale bar, $2 \mathrm{~mm}$.

dual and interacting effects on the dopamine-containing neurons there. Though macroscopic colocalization obviously does not prove cellular colocalization, it is of great interest in view of the similarity of certain sigma actions to dopamine autoreceptor activity. It is D2 receptors that are thought to mediate dopamine autoreceptor effects in the substantia nigra. Proximity of D2 sites and sigma sites on the same neurons and even the coupling of sigma sites to the D2 sites are possibilities that should be explored.

In contrast to the heightened D2-selective ligand binding in the densocellular zone, D1-selective ligand binding was low in this sigma-rich zone and higher elsewhere in the nigral complex, including the zone immediately ventral to the densocellular zone and possibly overlapping its most ventral limits (see also Besson et al., 1988). These Dl sites are thought to lie mainly on the terminals of striatonigral fibers, rather than on nigral neurons (Filloux et al., 1987). The sigma binding in the pars reticulata and other parts of the nigral complex outside the densocellular zone was moderate or low. Accordingly, though our findings do not point to marked focal overlap between dense sigma binding and D1 binding as they do for the sigma sites and D2 binding, the distributions leave open the possibility of functional interplay between D1 sites and sigma sites in a more widely distributed nigral zone.

Given the psychotomimetic and antipsychotic effects of sigma-selective drugs, it would have been natural to predict particularly dense sigma binding in the ventral tegmental area rather than in the substantia nigra proper. The ventral tegmental area is known to be the main (though not the exclusive) source of the dopamine-containing innervation of the nucleus accumbens and associated basal striatal tissue. These ventral striatal regions have been defined by their close ties to the limbic system (Heimer and Wilson, 1975) and have been implicated by some as potential sites of malfunction in schizophrenia (Matthysse,

$D / F-B-E$ with 2 sections skipped between $D / F$ and $B$ and between $B$ and $E$. Nuclear regions are identified in $C$. In each panel, a fiducial line marked by an asterisk indicates the densocellular zone of the substantia nigra pars compacta, and a fiducial arrowhead marks with its tip the level of the ventral limit of intense ${ }^{3} \mathrm{H}-\mathrm{SCH} 23390$ binding (B) that mainly underlies the densocellular zone. With these landmarks it can be seen that ${ }^{3} \mathrm{H}$-DTG binding and ${ }^{3} \mathrm{H}$-sulpiride binding are heightened in the densocellular zone, whereas ${ }^{3} \mathrm{H}-\mathrm{SCH} 23390$ and ${ }^{3} \mathrm{H}$-naloxone binding are denser slightly farther ventrally. $S N c(d z)^{*}$, substantia nigra pars compacta, densocellular zone; $S N l$, substantia nigra pars lateralis; $S N r$, substantia nigra pars reticulata; $A 8$, cell group A8; $I I I$, oculomotor complex; $R L$, rostral linear nucleus; $I P$, interpeduncular nucleus; $V T A$, ventral tegmental area. Densitometric measurements of binding in these sections is given in Table 1 . Scale bar, $2 \mathrm{~mm}$. 
1974). Levels of ${ }^{3} \mathrm{H}-\mathrm{DTG}$ binding were low in nearly all of the ventral tegmental region corresponding to the classic ventral tegmental area of Tsai (dorsolateral nucleus parabrachialis pigmentosis and ventromedial nucleus paranigralis). Heightened binding was present, however, in the midline and near-midline parts of the rostral raphe complex (the central and rostral linear nuclei), and there was particularly dense ${ }^{3} \mathrm{H}-\mathrm{DTG}$ binding in the interfascicular nucleus. There are dopamine-containing neurons in each of the labeled subdivisions, and each sends a fiber projection to limbic forebrain regions (Heimer and Wilson, 1975; Phillipson, 1979; Swanson, 1982). Thus, the present findings suggest that, at the level of the midbrain dopamine-containing cell groups, there is a highly selective pattern of sigmabinding within the limbic dopamine system. It will be interesting to determine whether this anatomical specificity bears any relation to the particular psychotomimetic effects of sigma-active compounds, including not only benzomorphans and phenothiazines but also steroids.

The dense ${ }^{3} \mathrm{H}$-DTG binding we observed in the substantia nigra's densocellular zone may also imply special linkage to the limbic system, but a linkage of another sort. Anterograde experiments in the cat strongly suggest that the densocellular zone projects preferentially to the striosomal compartment of the striatum, a differentiated striatal subsystem closely affiliated in the cat with certain parts of the limbic forebrain. Striosomes in this species are the main targets of striatal afferents originating in the basolateral amygdala (Ragsdale and Graybiel, 1988b), in parts of the prefrontal and insular cortex (Ragsdale and Graybiel, 1981, 1984), and in the limbic-related midline nuclei of the thalamus (Ragsdale and Graybiel, 1985, 1988a). Sigmaactive drugs, by binding to the putative striosome-projecting densocellular zone of the substantia nigra, could thus be exactly in a position to control these limbicostriatal pathways by modulating their dopaminergic input. Both the frontal cortex and the amygdala have been singled out as forebrain regions possibly implicated in the etiology of schizophrenia (Bird et al., 1979; Reynolds, 1983), as has the caudoputamen itself (Wong et al., 1986; Swerdlow and Koob, 1987; see also Early el al., 1987). This is not so for the cingulate gyrus, a part of the classic limbic system, which (like the ventral tegmental area) projects to the extrastriosomal matrix rather than to striosomes (Ragsdale and Graybiel, 1984; Donoghue and Herkenham, 1986).

The effects of any such sigma-mediated modulation of striosomes as proposed here would ultimately depend on the outputs of the striosomal system. These have been difficult to specify for technical reasons. Striosomes, being about the size of cortical columns and forming branched labyrinths, are difficult targets for anterograde tracer injections. Retrograde tracer injections into the known efferent targets of the striatum have been carried out (Graybiel et al., 1979; Gerfen, 1984; Jimenez-Castellanos and Graybiel, 1985, 1988; Gerfen et al., 1987), but subdivisions in these target zones-including those in the substantia nigraare difficult to inject selectively. What is certain is that it is the extrastriosomal matrix, not striosomes, that gives rise to the main efferent projections of the striatum to the globus pallidus and to the substantia nigra pars reticulata (Graybiel et al., 1979; Gerfen 1984; Jimenez-Castellanos and Graybiel, 1985; Fallon and Loughlin, 1987; Gerfen et al., 1987). The sole target so far identified for striosomal output is the medial part of the substantia nigra. In the rat, it is reported (Gerfen, 1984; Gerfen et al., 1987) that there is a direct projection from striosomes to the pars compacta. In the cat, the other species in which such tract tracing has been attempted, a medial nigral location has also been pinpointed as a striosomal target (Jimenez-Castellanos and Graybiel, 1985, 1988). The pars compacta, and especially its densocellular zone, is well developed in this medial site, but pars reticulata tissue also reaches this medial part of the substantia nigra; and, as shown here and elsewhere (Besson et al., 1988), the D1-selective ligand ${ }^{3} \mathrm{H}-\mathrm{SCH} 23390$, known to mark striatonigral afferents, binds in this ventral zone. If part or all of the striosomal system does project to the pars compacta in the cat, then sigma-mediated modulation of the densocellular zone could result in a chain of direct and indirect actions on nigrostriatonigral circuitry.

Very little is known of the inputs to the densocellular zone that might directly affect its neurons and their receptor sites without the mediation of other intervening axonal pathways. Interestingly, afferents to the caudomedial part of the pars compacta have been traced from the region of the dorsal tegmentum and raphe (Graybiel, 1977; Bobillier et al., 1979). A link between the raphe and the densocellular zone would extend the limbic affiliations of this nigral subdivision to a part of the limbic midbrain that itself displays considerable sigma ligand binding (Gundlach et al., 1986; McLean and Weber, 1988; and present results) and that is thought to be important in psychotomimetic drug effects (Aghajanian, 1981).

\section{${ }^{3} H-D T G$ binding in the striatum}

In accord with previous reports on the rat and guinea pig (Largent et al., 1984; Gundlach et al., 1985, 1986; McLean and Weber, 1988), we found relatively low levels of ${ }^{3} \mathrm{H}-\mathrm{DTG}$ binding in the striatum itself, either in its dorsal or ventral parts. This obscrvation suggests that sigma-mediated effects on the nigrostriatal system may be dominated by those depending on binding in the midbrain. It must be emphasized, however, that the binding in the striatum, though not dense, was appreciable. Experiments on the rat (Gundlach et al., 1986) suggest that as much as $80 \%$ of the sigma binding in the caudoputamen is affiliated with intrinsic striatal neurons rather than with dopamine-containing afferents (which might account for about $20 \%$ ). Independent actions at nigral and striatal levels would thus be indicated. Interestingly, the binding was so nearly uniform in the cat that the occasional hints of inhomogeneities in binding intensity were not considered convincing.

\section{Species specificity}

Our rationale for studying ${ }^{3} \mathrm{H}-\mathrm{DTG}$ binding in the feline nigrostriatal system was 2-fold. First, in the cat there is experimental evidence pointing to a particular nigral subdivison (the densocellular zone) as projecting to striosomes. Second, there is evidence in this species that patterns of D1 and D2 receptor-related ligand binding in the substantia nigra are correlated with this specialization of nigrostriatal connectivity. Our observations here suggest that sigma binding patterns may be related to both of these special features of nigral organization. Against these advantages stands the question of whether findings in the cat could inform the important issues surrounding the hallucinogenic and other psychotomimetic effects of sigma-selective ligands in the human and the mechanisms by which sigma-active drugs act in ameliorating schizophreniform symptoms. The fact that the psychotomimetic effects of sigma-receptor activation were originally identified in the dog (Martin et al., 1976) and were subsequently confirmed and extended in primates, including the human (Keats and Telford, 1964; Haertzen, 1970; Ma- 
tsumoto et al., 1987), suggests that at least some aspects of the expression of these receptors in brain may be phylogenetically conservative.

\section{References}

Aghajanian, G. K. (1981) The modulatory role of serotonin at multiple receptors in brain. In Serotonin Neurotransmission and Behavior, B. L. Jacobs and A. Gelperin, eds., pp. 156-185, MIT Press, Cambridge, MA.

Arnt, J., K. P. Bogeso, A. V. Christensen, J. Hyttel, J.-J. Larsen, and O. Svendsen (1983a) Dopamine receptor agonistic and antagonistic effects of 3-PPP enantiomers. Psychopharmacology 81: 199-207.

Arnt, J., A. V. Christensen, J. Hyttel, J.-J. Larsen, and O. Svendsen (1983b) Effects of putative dopamine autoreceptor agonists in pharmacological models related to dopaminergic and neuroleptic activity. Eur. J. Pharmacol. 86: 185-198.

Beckstead, R. M. (1987) The distributions of dopamine D1 and D2 receptors are partially complementary in the cat basal ganglia. Soc. Neurosci. Abstr. 13: 190.

Berman, A. L. (1968) The Brainstem of the Cat. A Cytoarchitectonic Atlas with Stereotaxic Coordinates, University of Wisconsin Press, Madison, WI.

Besson, M.-J., A. M. Graybiel, and M. Nastuk (1988) SCH 23390 ligand binding for striatal D1 dopamine receptors: Distribution follows striosomal ordering in cat, monkey and human. Neuroscience (in press).

Bird, E. D., T. J. Crow, and L. L. Iversen (1979) Increascd dopaminc concentrations in limbic areas of brain from patients dying with schizophrenia. Brain 102: 347-360.

Bobillier, P., A. Seguin, A. Degueurce, B. D. Lewis, and J. F. Pujol (1979) The efferent connections of the nucleus raphe centralis superior in the rat as revealed by autoradiography. Brain Res. 166: 1-8.

Campbell, B. G., D. H. Bobker, F. M. Leslie, I. N. Mefford, and E. Weber (1987) Both the sigma receptor-specific ligand (+)3-PPP and the PCP receptor-specific ligand TCP act in the mouse vas deferens via augmentation of electrically evoked norepinephrine release. Eur. J. Pharmacol. 138: 447-449.

Clark, D., D. Hjorth, and A. Carlsson (1985) Dopamine-receptor agonists: Mechanisms underlying autoreceptor sensitivity. I. Review of the evidence. J. Neural Transmission 62: 1-52.

Donoghue, J. P., and M. Herkenham (1986) Neostriatal projections from individual cortical fields conform to histochemically distinct striatal compartments in the rat. Brain Res. 365: 367-403.

Early, T. S., E. M. Reiman, M. E. Raichle, and E. L. Spitznagel (1987) Left globus pallidus abnormality in never-medicated patients with schizophrenia. Proc. Natl. Acad. Sci. USA 84: 561-563.

Fallon, J. H., and S. E. Loughlin (1987) Monoamine innervation of cerebral cortex and a theory of the role of monoamines in cerebral cortex and basal ganglia. In Cerebral Cortex. Vol. 6, E. G. Jones and A. Peters, eds., pp. 41-127, Plenum, New York.

Filloux, F. M., J. K. Wamsley, and T. M. Dawson (1987) Presynaptic and postsynaptic D1 dopamine receptors in the nigro-striatal system of the rat brain: A quantitative autoradiographic study using the selective D1 antagonist [ $\left.{ }^{3} \mathrm{H}\right] \mathrm{SCH} 23390$. Brain Res. 408: 283-288.

Gehlert, D. R., and J. K. Wamsley (1985) Dopamine receptors in rat brain: Quantitative autoradiographic localization using $\left[{ }^{3} \mathrm{H}\right]$ sulpiride. Neurochem. Int. 7: 717-723.

Geneser-Jensen, F. A., and J. W. Blackstad (1971) Distribution of acetylcholinesterase in the hippocampal region of the guinea pig. $Z$. Zellforsch Mikrosk. Anat. 114: 460-481.

Gerfen, C. R. (1984) The neostriatal mosaic: Relationships among striatal input, output and peptidergic systems. Nature 311: 461-464.

Gerfen, C. R., M. Herkenham, and J. Thibault (1987) The neostriatal mosaic: II. Patch-and matrix-directed mesostriatal dopaminergic and non-dopaminergic systems. J. Neurosci. 7: 3915-3934.

Graybiel, A. M. (1977) Direct and indirect preoculomotor pathways of the brainstem: An autoradiographic study of the pontine reticular formation in the cat. J. Comp. Neurol. 175: 37-78.

Graybiel, A. M., and R. P. Elde (1983) Somatostatin-like immunoreactivity characterizes neurons of the nucleus reticularis thalami in the cat and monkey. J. Neurosci. 3: 1308-1321.

Graybiel, A. M., and C. W. Ragsdale (1978) Histochemically distinct compartments in the striatum of human, monkey, and cat demon- strated by acetylthiocholinesterase staining. Proc. Natl. Acad. Sci. USA 75: 5723-5726.

Graybiel, A. M., C. W. Ragsdale, and S. Moon Edley (1979) Compartments in the striatum of the cat observed by retrograde celllabelling. Exp. Brain Res. 34: 189-195.

Graybiel, A. M., E. Weber, M.-J. Besson, and K. Karuzis (1987a) Haloperidol-sensitive sigma receptors in the substantia nigra pars compacta: Autoradiographic evidence for specific anatomical localization of $\left[{ }^{3} \mathrm{H}\right] \mathrm{DTG}$ binding sites. Soc. Neurosci. Abstr. 13: 28.

Graybiel, A. M., E. Hirsch, and Y. A. Agid (1987b) Differences in tyrosine hydroxylase-like immunoreactivity characterize the mesostriatal innervation of striosomes and extrastriosomal matrix at maturity. Proc. Natl. Acad. Sci. USA 84: 303-307.

Gundlach, A. L., B. L. Largent, and S. H. Snyder (1985) Phencyclidine and sigma opiate receptors in brain: Biochemical and autoradiographical differentiation. Eur. J. Pharmacol. 113: 465-466.

Gundlach, A. L., B. L. Largent, and S. H. Snyder (1986) Autoradiographic location of sigma receptor binding sites in guinea pig and rat central nervous system with $(+)^{3} \mathrm{H}-3-(3-H y d r o x y p h e n y l)-\mathrm{N}-(1$-propyl)piperidine. J. Neurosci. 6: 1757-1770.

Haertzen, C. A. (1970) Subjective effects of narcotic antagonists cyclazocine and nalorphine on the addiction research center inventory (ARCI). Psychopharmacologia (Berl.) 18: 366-377.

Heimer, L., and R. D. Wilson (1975) The subcortical projections of the allocortex: Similarities in the neural associations of the hippocampus, the piriform cortex, and the neocortex. In Golgi Centennial Symposium Proceedings, M. Santini, ed., pp. 177-193, Raven, New York.

Hcrkenham, M., and C. B. Pcrt (1982) Light microscopic localization of brain opiate receptors: A general autoradiographic method which preserves tissue quality. J. Neurosci. 2: 1129-1149.

Hjorth, S., A. Carlsson, H. Wikstrom, P. Lindberg, D. Sanchez, U. Hacksell, L. E. Arvidsson, U. Svensson, and J. L. G. Nilsson (1981) 3-PPP, a new centrally acting DA-receptor agonist with selectivity for autoreceptors. Life Sci. 28: 1225-1238.

Hjorth, S., A. Carlsson, D. Clark, K. Svensson, H. Wikstrom, D. Sanchez, P. Lindberg, and U. Hacksell (1983) Central dopamine receptor agonist and antagonist actions of the enantiomers of 3-PPP. Psychopharmacology 81: 89-99.

Hjorth, S., D. Clark, and A. Carlsson (1985) Lack of functional evidence for the involvement of sigma opiate receptors in the actions of the 3-PPP enantiomers on central dopaminergic systems: Discrepancies between in vitro and in vivo observations. Life Sci. 37: 673684.

Iwamoto, E. T. (1981) Locomotor activity and antinociception after putative mu, kappa, and sigma opioid receptor agonists in the rat: Influence of dopaminergic agonists and antagonists. J. Pharmacol. Exp. Ther. 217: 451-460.

Jimenez-Castellanos, J., and A. M. Graybiel (1985) The dopaminecontaining innervation of striosomes: Nigral subsystems and their striatal correspondents. Soc. Neurosci. Abstr. 11: 1249.

Jimenez-Castellanos, J., and A. M. Graybiel (1987) Subdivisions of the dopamine-containing A8-A9-A10 complex identified by their differential mesostriatal innervation of striosomes and extrastriosomal matrix. Neuroscience 23: 223-242.

Joyce, J. N., D. W. Sapp, and J. F. Marshall (1986) Human striatal dopamine receptors are organized in compartments. Proc. Natl. Acad. Sci. USA 83: 8002-8006.

Kavanaugh, M. P., B. A. C. Tester, J. F. W. Keana, and E. Weber (1987) The sigma-selective photoaffinity ligand $\left[{ }^{3} \mathrm{H}\right]$ azido-ditolylguanidine specifically labels a $29 \mathrm{kD}$ polypeptide from guinea pig brain membranes. Soc. Neurosci. Abstr. 13: 1704.

Keats, A. S., and J. Telford (1964) Narcotic antagonists as analgesics, clinical aspects. In Molecular Modification in Drug Design: Advances in Chemistry, R. F. Gould, ed., pp. 170-176, American Chemical Society, Washington, D.C.

Largent, B. L., A. L. Gundlach, and S. H. Snyder (1984) Psychotomimetic opiate receptors labeled and visualized with $(+)-\left[{ }^{3} \mathrm{H}\right] 3-(3-$ hydroxyphenyl)-N-(1-propyl)piperidine. Proc. Natl. Acad. Sci. USA 81: 4983-4987.

Largent, B. L., A. L. Gundlach, and S. H. Snyder (1986) Pharmacological and autoradiographic discrimination of sigma and phencyclidine receptor binding sites in brain with $(+)-\left[{ }^{3} \mathrm{H}\right] \mathrm{SKF}-10,047,(+)$ [3H]-3-[3-hydroxyphenyl]-N-(1-propyl)piperidine. J. Pharmacol. Exp. Ther. 238: 739-748. 
Lewis, M. E., H. Khachaturian, and S. J. Watson (1982) Visualization of opiate receptors and opioid peptides in sequential brain sections. Life Sci. 31: 1347-1350.

Lowry, O. H., N. J. Rosebrough, A. L. Farr, and R. J. Randall (1951) Protein measurement with the folin phenol reagent. J. Biol. Chem. 193: 265-275.

Martin, W. R. (1981) Mini-symposium: Multiple opioid receptors, a little about their history and some implications related to evolution. Life Sci. 28: 1547-1554.

Martin, W. R., C. G. Eades, J. A. Thompson, R. E. Huppler, and P. E. Gilbert (1976) The effects of morphine- and nalorphine-like drugs in the nondependent and morphine-dependent chronic spinal dog. J. Pharmacol. Exp. Ther. 197: 517-532.

Matsumoto, R. R., R. D. Bowen, D. L. Gans, K. D. Jones, F. O. Walker, and J. M. Walker (1987) Motor and postural effects of haloperido and other sigma ligands at a non-dopaminergic receptor site. Soc. Neurosci. Abstr. 13: 599.

Matthysse, S. (1974) Schizophrenia: Relationships to dopamine transmission, motor control, and feature extraction. In The Neurosciences: Third Study Program, F. O. Schmitt and F. G. Worden, eds., pp. 733-737, MIT Press, Cambridge, MA.

McLean, S., and E. Weber (1988) Autoradiographic visualization of haloperidol-sensitive sigma receptors in guinea-pig brain. Neuroscience 25: 259-269.

Mehler, W. R. (1980) Subcortical afferent connections of the amygdala in the monkey. J. Comp. Neurol. 190: 733-762.

Phillipson, O. T. (1979) The cytoarchitecture of the interfascicular nucleus and ventral tegmental area in the rat. J. Comp. Neurol. 187: 85-98

Poirier, L. J., M. Giguere, and R. Marchand (1983) Comparative morphology of the substantia nigra and ventral tegmental area in the monkey, cat, and rat. Brain Res. Bull. 11: 371-397.

Ragsdale, C. W., and A. M. Graybiel (1981) The fronto-striatal projection in the cat and monkey and its relationship to inhomogeneities established by acetylcholinesterase histochemistry. Brain Res. 208 259-266.

Ragsdale, C. W., and A. M. Graybiel (1984) Further observations on the striosomal organization of frontostriatal projections in cats and monkeys. Soc. Neurosci. Abstr. 10: 514.

Ragsdale, C. W., and A. M. Graybiel (1985) Evidence in the cat that thalamostriatal fibers innervate striosomes or matrix tissue according to their site of origin. Soc. Neurosci. Abstr. 11: 203.

Ragsdale, C. W., and A. M. Graybiel (1988a) Multiple patterns of thalamostriatal innervation in the cat. In Cellular Thalamic Mechanisms, M. Bentivoglio, G. Macchi, and R. Spreafico, eds., Elsevier, Amsterdam.

Ragsdale, C. W., and A. M. Graybiel (1988b) Fibers from the basolateral nucleus of the amygdala selectively innervate striosomes in the caudate nucleus of the cat. J. Comp. Neurol. 269: 506-522.

Reynolds, G. P. (1983) Increased concentrations and lateral asymmetry of amygdala dopamine in schizophrenia. Nature 305: 827-830.

Richfield, E. K., A. B. Young, and J. B. Penney (1987) Comparative distribution of dopamine D1 and D2 receptors in the basal ganglia of turtles, pigeons, rats, cats, and monkeys. J. Comp. Neurol. 262: 446-463.

Sircar, R., R. Nichtenhauser, J. R. Ieni, and S. R. Zukin (1986) Charactcrization and autoradiographic visualization of $(+)-\left[{ }^{3} \mathrm{H}\right] \mathrm{SKF} 10,047$ binding in rat and mouse brain: Further evidence for phencyclidine/ "sigma opiate" receptor commonality. J. Pharmacol. Exp. Ther. 237. 681-688.

Sonders, M., N. Hendrickson, and E. Weber (1987) The selective sigma ligand $\left[{ }^{3} \mathrm{H}\right]-\mathrm{DTG}$ binds to sites in human and guinea pig cerebella with distinct pharmacological profiles. Soc. Neurosci. Abstr. 13: 1703.

Su, T. P. (1982) Evidence for sigma opioid receptors: Binding of $\left[{ }^{3} \mathrm{H}\right] \mathrm{SKF}-10,047$ to etorphine-inaccessible sites in guinea-pig brain. J. Pharmacol. Exp. Ther. 223: 284-290.

Su, T. P., E. D. London, and J. H. Jaffe (1988) Steroid binding at sigma receptors suggests a link between endocrine, nervous, and immune systems. Science 240: 219-221.

Swanson, L. W. (1982) The projections of the ventral tegmental area and adjacent regions: A combined fluorescence retrograde tracer and immunofluorescence study in the rat. Brain Res. Bull. 9: 321-353.

Swerdlow, N. R., and G. F. Koob (1987) Dopamine, schizophrenia, mania, and depression: Toward a unified hypothesis of cortico-striatopallido-thalamic function. Behav. Brain Sci. 10: 197-245.

Tam, S. W. (1985) (+)-| $\left.\left.\right|^{3} \mathrm{H} J \mathrm{SKF} 10,047,(+)-\left.\right|^{3} \mathrm{H}\right]$ Ethyl-ketocyclazocine, mu, kappa, sigma and phencyclidine binding sites in guinea pig brain membranes. Eur. J. Pharmacol. 109: 33-41.

Tam, S. W., and L. Cook (1984) Sigma opiates and certain antipsychotic drugs mutually inhibit $(+)-\left[{ }^{3} \mathrm{H}\right] \mathrm{SKF} 10,047$ and $\left[{ }^{3} \mathrm{H}\right]$ haloperidol binding in guinea pig brain membranes. Proc. Natl. Acad. Sci. USA 81: 5618-5621.

Vaupel, D. B. (1983) Naltrexone fails to antagonize the effects of PCP and SKF 10,047 in the dog. Eur. J. Pharmacol. 92: 269-274.

Vaupel, D. B., and T. P. Su (1987) Guinea-pig vas deferens preparation may contain both sigma receptors and phencyclidine receptors. Eur. J. Pharmacol. 139: 125-128.

Vu, T. H., A. D. Weissman, and E. D. London (1987) Phylogenetic distribution of haloperidol-sensitive sigma and phencyclidine binding sites in the nervous system. Soc. Neurosci. Abstr. 13: 1703.

Weber, E., M. Sonders, M. Quarum, S. Pou, and J. F. W. Keana (1986a) [ $\left.{ }^{3} \mathrm{H}\right] 1,3-\mathrm{Di}$-o-tolyl-guanidine ([$\left.\left.{ }^{3} \mathrm{H}\right]-\mathrm{DTG}\right)$, a novel, selective ligand for the haloperidol sensitive sigma (opioid) receptor. Soc. Neurosci. Abstr. 12: 172 .

Weber, E., M. Sonders, M. Quarum, S. McLean, S. Pou, and J. F. W. Keana (1986b) 1,3-Di(2-[5- $\left.{ }^{3} \mathrm{H}\right]$ tolyl)guanidine: A selective ligand that labels sigma-type receptors for psychotomimetic opiates and antipsychotic drugs. Proc. Natl. Acad. Sci. USA 83: 8784-8788.

Wong, D. F., H. N. Wagner, L. E. Tune, R. F. Dannals, G. D. Pearlson, J. M. Links, C. A. Tamminga, and E. P. Broussolle (1986) Positron emission tomography reveals elevated $\mathrm{D}(2)$ dopamine receptors in drug-naive schizophrenics. Science 234: 1558-1563.

Zukin, S. R., K. T. Brady, B. L. Slifer, and R. L. Balster (1984) Behavioral and biochemical stereoselectivity of sigma opiate/PCP receptors. Brain Res. 294: 174-177. 